\title{
comentario
}

\section{Información y conocimiento, otra vinculación}

Los procesos de cambio y transformación que caracterizan a la época contemporánea, están alterando cualitativa men te los ob je ti vos de los cen tros de difu sión de lain for ma ción pues, a diferen cia de la de man da de ex pan sión e introducción de nuevas tecnologías a la que fueron sometidas las bibliotecas a mitad del siglo por el llamado "Boom" de la información, la opor tu ni dad de la in for ma ción para que los in di viduoses tén al día, ac tual men te no es suficiente ya que la dinámica de los acontecimientos involucran un factor de inestabilidad que se acrecienta con el cúmulo de información sobre las distintas variantes del cambio.

Paralelo a estos cambios va apareciendo, como un conocimiento cada vez más estable aunque con contenido amenazador, la certeza científica de que el planeta está en peligro de alterar radicalmente su ecosistema a causa de ha ber re du ci do nues tros ac tos a la in me dia tez, al día, y no ver sus con se cuen cias a largo pla zo y con res pec to a la totalidad de seres y cosas en que nuestra actividad se inscribe.

Se está ge ne ran do así un pro ce so de tran si ción de lo in di vi dual a lo co mu ni tario bajo eles que ma de la soli da ri dad interhumana; de lo lo cal a lo in ter na cio nal so bre la bú s que da de la co o pe ra ción in ternacional; de lo artificial a lo natural sin perder loque his tórica men te el ser hu ma no halogra do de po si ti vo res ca tan do del pa sa do aquellas formas de ac ción y pro duc ción que no aten ta ban, ni a cor to ni a lar go pla zo, con la vida, la n a tu ra le za y elplane ta.

Es cla ro que el sen ti do que está ad qui rien do esta tran si ción no re quie re sólo de in for ma ción opor tu nay ade cua da, sino bá si ca men te de co no ci mien tos dis po ni bles a todo usua rio que le lle ven a la re flexión so bre el sen ti do de sus actos en elfuturo. Conoci mien tocien tíficoy hu manís ticoque tra di cionalmen te ha sidocon serva do y trans mi tido por las bibliotecas.

Hoy las bibliotecas, como centros de información, de documentación, etc., tienen un doble reto: mantener al día los servicios informativos y, a la vez, generar el interés en los conocimientos que traigan el bienestar al hombre con todo lo vivo y todo el planeta; de tal forma que así como las ideas más avanzadas del mundo contemporáneo es ta ble cen que ya no se tra ta de in ves ti gar por el sólo he cho de ha cer lo, sino de con ciliar éti ca men te los fi nes de la investigación con el bien humano y natural, tampoco se trata tan sólo de transmitir información sin importar el uso que se le dé, sino de saber guiar al usuario en aquello que satisfaga su necesidad de conocimiento humano, natural y planetario.

Las biblio te cas, como to das las ins ti tu ciones con tem poráneas, no pue den ais lar se del ca rác ter éti co que está asumiendo la adquisición y uso del conocimiento hacia la conformación del mundo del futuro. 